\title{
A FORMAÇÃO DE CONCEITOS CIENTÍFICOS: REFLEXÕES A PARTIR DA PRODUÇÃO DE LIVROS DIDÁTICOS
}

\author{
The development of scientific concepts: \\ reflections from a textbook writing experience
}

\author{
Maria Emília Caixeta de Castro Lima ${ }^{1}$ \\ Orlando Aguiar Júnior ${ }^{2}$ \\ Carmen Maria De Caro ${ }^{3}$
}

\begin{abstract}
Resumo: Este trabalho sistematiza reflexões que orientaram a produção de texto didático de ciências de modo a encorajar os estudantes a desenvolverem conceitos científicos fundamentais. Apoiamo-nos em Vygotsky e Bakhtin para afirmarmos nossa convicção de que os sentidos das palavras não se resolvem em glossários, mas por meio de seu uso em contextos sociais específicos. Apresentamos exemplos, extraídos do texto didático, de estratégias elaboradas com o intuito de se estabelecerem pontes entre os sentidos pessoais, presentes no cotidiano dos estudantes, e os conceitos científicos, com significados mais estabilizados.
\end{abstract}

Palavras-chave: Livro didático. Formação de conceitos. Socioconstrutivismo, linguagem e cognição.

\begin{abstract}
This paper presents a systematization of the reflections that guided our decisions about how to design a science textbook that best encouraged students to develop basic scientific concepts. We drew upon the theories of Vygotsky and Bakhtin to support our conviction that what a word means is not revealed in a dictionary, but in its use in social contexts. We present extracts from a science textbook, exemplifying strategies aimed at establishing mediations between personal meanings relied on in the everyday life of the students and the scientific concepts with more stable meanings.

Keywords: Textbook. Concept formation. Social-constructivism, language and cognition.
\end{abstract}

\footnotetext{
${ }^{1,2}$ Doutores em Educação. Docentes, Departamento de Métodos e Técnicas de Ensino, Faculdade de Educação, Universidade Federal de Minas Gerais (UFMG), Belo Horizonte, MG, Brasil.

<mecdcl@uol.com.br>; <orlando@fae.ufmg.br>

${ }^{2}$ Doutora em Educação. Docente, Setor de Biologia, Colégio Técnico, UFMG. Belo Horizonte, MG, Brasil.

<carmen@coltec.ufmg.br>
}

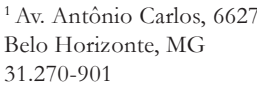




\section{Introdução}

Um dos temas de grande interesse da pesquisa em educação em ciências é a formação e o desenvolvimento de conceitos científicos pelos estudantes. A produção de conhecimentos sobre o processo de ensino e aprendizagem em sala de aula tem se apoiado largamente nas contribuições de Vygotsky (FONTANA, 1996; WERTSCH, 1998; MACHADO, 1999; MORTIMER, 2000; FREITAS, 1995). Em que pese o grande número e alcance de trabalhos publicados, bem como a diversidade de orientações teóricas dos mesmos, a produção acadêmica neste campo pouco tem influenciado na elaboração dos textos didáticos de ciências nos vários níveis de ensino.

Neste trabalho, examinamos o processo de formação e desenvolvimento de conceitos científicos balizado por nossa experiência como autores de textos didáticos de ciências ${ }^{4}$, como formadores de professores e como professores de ciências nos níveis Fundamental, Médio e Superior. A importância por nós atribuída à formação de conceitos não é considerada como meta única da educação em ciências. Ao contrário, entendemos que o aprendizado de conceitos em ciências não pode ser dissociado de outras metas curriculares, como: aprender os procedimentos de produção de conhecimento em ciências (por meio de investigação orientada e da argumentação baseada em evidências) e aprender sobre a relação ciência-tecnologia-sociedade.

$\mathrm{Na}$ análise do livro didático, nos valemos essencialmente das contribuições de Vygotsky (2001) e Bakhtin (1981, 1997a, 1997b). Enquanto Vygotsky (2001) nos auxilia na compreensão do processo de internalização dos conceitos espontâneos e científicos como prática social mediada pedagógica e intencionalmente planejada, Bakhtin (1997a) orienta nossa atenção para a natureza ideológica dos signos que circulam em contextos sociais específicos. Por isso, pensar a educação no contexto da escola como instituição de práticas e de circulação de discursos específicos, nos fez buscar, também, as contribuições desse autor. Bakhtin "valoriza justamente a fala, a enunciação e afirma sua natureza social, não individual: a fala está indissoluvelmente ligada às condições da comunicação que, por sua vez, estão sempre ligadas às estruturas sociais" (YAGUELLO, 1997, p. 11). A formação de conceitos científicos na escola se dá por meio de processos dialógicos estruturados a partir de sujeitos que ocupam lugares diferentes e historicamente referenciados pelos significados atribuídos aos conteúdos do currículo.

\section{A diferença entre conceituação e definição}

A prática corrente e tradicional no ensino de ciências consiste em apresentar um conjunto de definições, seguidas de alguns exemplos, e uma profusão de exercícios, com pou-

\footnotetext{
${ }^{4}$ A experiência aqui analisada refere-se à escrita da coleção "Construindo Consciências", editada pela Scipione, e aprovada para o PNLD 2008 (AÇÃO E PESQUISA EM EDUCAÇÃO EM CIÊNCIAS, 2007). O Grupo Ação e Pesquisa na Educação em Ciências (APEC) é constituido pelos autores deste artigo e pelos professores Helder Figueiredo e Paula, Mairy Barbosa Loureiro, Nilma Soares da Silva, Ruth Schmitz Castro e Selma Moura Braga.
} 
A formação de conceitos científicos: ...

cas variações entre eles, para fixação dos conteúdos apresentados. Nessa perspectiva, o procedimento de ensino restringe-se à apresentação de conteúdos factuais, classificações, fórmulas e nomes ou meras definições de entidades químicas, físicas ou biológicas, tais como: elemento, substância, soluções, corrente elétrica, inércia, gens, gametas etc.

A concepção de ensino que orienta essas práticas se assenta na lógica da explicação acabada, sem levar em conta o sujeito que aprende e o processo de significação dos conceitos científicos. Tal lógica se estabelece como um mecanismo de transferência de conhecimentos prontos, cristalizados e sistematizados por meio da apresentação de definições. A partir do referencial teórico vygotskyano, tecemos muitas críticas a esta perspectiva e concordamos com o autor quando nos diz que

Uma das principais fragilidades do método de definição [utilizado em psicologia experimental] é o fato de que o conceito é retirado de uma relação natural, em forma estagnada, fora do vínculo com os processos reais de pensamento em que surge, é descoberto e vive [...] tomada em forma estagnada não nos dá a mínima idéia do que seja a palavra em ação, de modo que a criança opera com ela no processo vivo de solução de um problema, de como a emprega quando para isso surge a necessidade viva. (VIGOTSKY, 2001, p. 154)

Desse modo, memorizar uma definição correta não garante a compreensão das muitas relações nela envolvidas. Afinal, a aprendizagem de conceitos é algo muito mais complexo do que a simples proposição de definições consagradas em textos didáticos, em glossários e notas de aulas. "A definição de um conceito é uma síntese, a formalização de certas relações que já estão, de certo modo, compreendidas por parte de quem as formula" (LIMA; SILVA, 2007, p. 102). É produto de uma compreensão sintética, acabada e formalizada.

Mas como se dá a formação e evolução de conceitos científicos pelos estudantes? Para responder a essa questão, nos valemos dos estudos de Vygotsky $(1991,2001)$ sobre a construção dos conceitos científicos, e em Bakhtin (1997b) no que se refere ao papel dos signos na produção de sentidos. Para Vygotsky (1991, p. 72),

[...] a experiência prática mostra que o ensino direto de conceitos é impossível e infrutífero. Um professor que tenta fazer isso geralmente não obtém qualquer resultado, exceto o verbalismo vazio, uma repetição de palavras pela criança, semelhante à de um papagaio, que simula um conhecimento dos conceitos correspondentes, mas que na realidade oculta um vácuo.

Nesse texto, Vygotsky (1991) cita Tolstoi, que se reporta às suas vivências como educador:

Quando ela [a criança] ouve ou lê uma palavra desconhecida numa frase, de resto compreensível, e a lê novamente em outra frase, começa a ter uma idéia vaga de um novo conceito: mais cedo ou mais tarde ela 
Lima, M. E. C. C.; Aguiar Júnior, O.; De Caro, C. M.

[...] sentirá a necessidade de usar essa palavra - e uma vez que a tenha usado, a palavra e o conceito lhe pertencem [...] Mas, transmitir deliberadamente novos conceitos ao aluno [...] é, estou convencido, tão impossível e inútil quanto ensinar uma criança a andar apenas por meio das leis do equilíbrio. (TOLSTOI, 1903 apud VYGOTSKY, 1991, p. 72)

É preciso ainda lembrar da especificidade e da natureza dos conceitos científicos. Segundo Marta Kohl Oliveira (1999):

[...] a ciência trabalha com a construção de categorias formalizadas, de organização de seus objetos e com processos deliberados de generalização, buscando leis e princípios universais, estruturados em sistemas teóricos com clara articulação interna. [...] a esfera da ciência é claramente diferente da esfera da vida cotidiana e do senso comum, na medida em que se afasta do que é particular, contextualizado, referente à experiência individual e às necessidades imediatas. (OLIVEIRA, 1999, p. 58-59)

A aquisição dos conceitos não guarda um fim em si mesma. Tal como afirmado por Vygotsky (2001, p. 154), ao retomar Ach, um dos seus interlocutores, um conceito "sempre exerce uma função de comunicar, assimilar, entender e resolver algum problema". Em outras palavras, admitimos que "[...] um conceito surge e se configura no curso de uma operação complexa voltada para a solução de um problema e que só a presença de condições externas e o estabelecimento mecânico de uma ligação entre a palavra e o objeto não são suficientes para a criação de um conceito" (VIGOTSKY, 2001, p. 156).

A aprendizagem dos conceitos constitui elemento central da educação em ciências. Os conceitos são os instrumentos mediacionais por meio dos quais interpretamos e interagimos com as realidades que nos cercam. Bakhtinianamente falando, agimos e vivemos pela palavra. Por correspondência, podemos dizer que, em ciências, produzimos novos conhecimentos, compreendemos e explicamos os fenômenos e os produtos tecnológicos por meio de uma rede conceitual. Pensamos por conceitos. Em outras palavras, os conceitos são ferramentas que utilizamos para pensarmos o mundo e a nós mesmos, para agirmos no mundo e interagirmos com ele e com os outros. Por outro lado, essa ação sobre as realidades a serem interpretadas e transformadas nos leva a rever constantemente os conceitos aprendidos. Assim, os conceitos vão se modificando, tanto em extensão quanto em compreensão, num processo lento e difícil de produção de sentidos e de confronto com os significados socialmente estabelecidos.

O processo de formação de conceitos científicos envolve a apropriação, pelos estudantes, dos novos modos de falar e pensar o mundo. Baseando-nos na Filosofia da Linguagem de M. Bakhtin (1997b), a compreensão da palavra alheia é resultado de um processo de confronto e interpretação, o que proporciona uma reavaliação, uma modificação e o surgimento de um novo signo na consciência, uma nova palavra interior (BRAIT, 2005). Assim, podemos entender a formação de conceitos como trabalho social e semiótico. Sua apropriação resulta de um esforço de relacionar um signo interior qualquer de que dispomos com a unicidade de outros signos que nos são apresentados no contexto social de uso e significados (BRAIT, 1997a). 
A compreensão dos conceitos depende de, pelo menos, dois sujeitos. A palavra é o território comum do locutor e do interlocutor, ponte lançada entre o eu e os outros (BAKHTIN, 1997a, p. 113). São sentidos que se entrecruzam, complementam, refletem e refratam. Contudo, há que se considerar que a produção de sentidos não pressupõe, necessariamente, a presença física de um outro. Mesmo quando estamos sozinhos, carregamos conosco outros textos, autores, pessoas que fazem parte do nosso universo social de significação do mundo. Portanto, todo processo de formação de conceitos é, essencialmente, dialógico e dependente das estratégias de mediação adotadas.

$\mathrm{Na}$ escrita da coleção de livros didáticos aqui analisada, nos valemos dessa concepção de ensino e de aprendizagem ao considerarmos a linguagem como constitutiva do pensamento. A opção que fizemos foi de evitar definições prontas e descontextualizadas. Apostamos num sujeito da aprendizagem interativo e falante, que vai sendo introduzido a um novo modo de falar e compreender o mundo. Compartilhamos com MORTIMER (2000) a ideia de que aprender ciências implica entrar em um mundo que se apresenta com uma linguagem própria, bem como tomar consciência das diferenças e das relações entre as linguagens da ciência e outras formas de falar e compreender o mundo.

Aprender conceitos, nessa perspectiva, é um processo lento, complexo e sempre inacabado, pois os conceitos vão sendo revistos e ampliados. Por exemplo, o conceito de átomo significava, para Dalton, a unidade indivisível. O conceito foi retomado e modificado repetidas vezes na história da química. O átomo deixou de ser indivisível, mas nos reportamos a ele usando a mesma palavra. Do mesmo modo como os conceitos mudam ao longo da história do pensamento científico, os sentidos que vamos construindo acerca deles também mudam. Entende-se por sentidos os modos pessoais de compreender ou se apropriar de um conceito, enquanto os significados são os sentidos que se estabilizam com o tempo, fruto de uma construção e acordo coletivos. Os sentidos, portanto, remetem aos indivíduos, e os significados, às comunidades científicas.

Enquanto as palavras duram, os sentidos mudam (LIMA, 2005). Desse modo, os conceitos não são categorias intrínsecas da mente, nem reflexo da experiência pessoal, mas produtos históricos da atividade mental. Segundo Fontana (1997, p. 13), "Os conceitos têm história. Carregam consigo as marcas e as contradições do momento histórico em que se desenvolveram e consolidaram, os movimentos de re-elaboração e de re-articulação no jogo das forças sociais... Marcas que estão impressas na própria palavra.

Em nossas produções didáticas, os leitores vão encontrar três possibilidades. Uma delas é a de se fazer uso de um conceito sem a pretensão de formalizá-lo em um dado momento. Esse é o caso do conceito de substância, sem o qual seria impossível entrar no universo da química, mas cuja definição formal ultrapassa as metas da educação em ciências no nível Fundamental.

Outras vezes, optamos por apresentar uma definição apenas ao final de um processo de aprendizagem como formalização de certas relações que já estão, de algum modo, compreendidas e consolidadas por quem as enuncia. O conceito científico de energia, ancorado na ideia de conservação, foi desenvolvido desse modo em um dos capítulos da coleção.

Em outros casos, a definição é apresentada inicialmente, como provocação de um novo modo de pensar. É o caso, por exemplo, das "funções de nutrição", apresentadas como princípio organizador de um conjunto de processos que envolvem a transformação dos ali- 
mentos no organismo e a obtenção de energia. Mesmo nesse caso, a apropriação desse novo conceito não está determinada pelo momento em que uma definição é apresentada, mas pelas mediações oportunizadas para a significação dos conceitos.

O processo de formação de conceitos nos remete ao "material que serve de base para sua formação e à palavra através da qual ele surge" (VIGOTSKY, 2001, p. 153). Um conceito além de não existir isolado, se constitui numa rede de outros, como produto de uma elaboração racional da experiência dos sujeitos. Em outras palavras, a crítica que fazemos ao ensino de ciências, tal como vem se configurando, não significa que uma definição não deva ser inicialmente apresentada, para, a partir dela, se produzir um sentido novo, mas aos modos como essa mediação é feita. Nesse sentido, o processo de formação de um conceito pode valer-se de uma definição tomada a priori como sendo o próprio material que servirá de base para as interações linguísticas e semiológicas. A medida da generalidade de um conceito se assenta na capacidade dos sujeitos de colocá-lo em um sistema global de inter-relações de sentidos. Resulta de generalizações em níveis diferentes de conceitos (VIGOTSKY, 2001, p. 9). Consiste em organizá-los em um sistema, tendo como critério o grau de generalização, o que está para além da simples memorização de definições isoladas.

Para exemplificar o que viemos argumentando, apresentamos condições funcionais de introdução e abordagem do conceito de substância para os estudantes, de acordo com a coleção em análise. Apresentamos como situação-problema a discussão da pureza da água mineral, extraída de fonte natural. A análise do rótulo do produto permite aos estudantes identificarem muitas "coisas" misturadas à água, embora ela lhes pareça "pura". O roteiro da atividade, que apresentamos na Figura 1, procurou colocar em circulação o conceito de substância nas trocas verbais na sala de aula em torno da situação-problema apresentada aos estudantes.

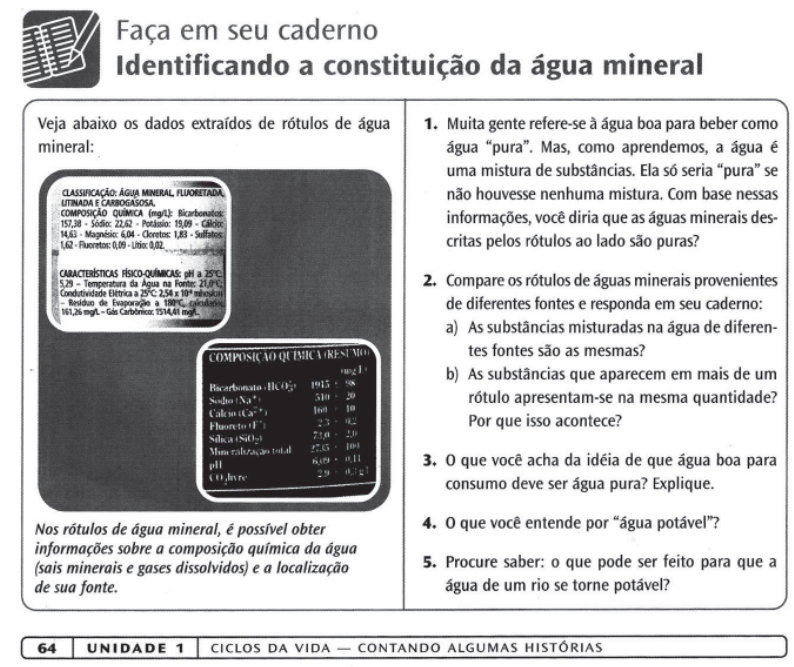

Figura 1. Atividade proposta na coleção para o desenvolvimento dos conceitos de substância e mistura.

Fonte: AÇÃO E PESQUISA EM EDUCAÇÃO EM CIÊNCIAS. Construindo consciências - ciências: $5^{a}$ série. São Paulo: Scipione, 2007. p. 64 
Para construir significados sobre algo desconhecido - o conceito de substâncias e misturas -, os autores optaram por criar certa correspondência entre o novo e o já conhecido. Os alunos, em geral, conhecem água mineral e sabem que ela é potável ou boa para se beber. Mas faz parte do senso comum a ideia de que "os alimentos puros são saudáveis, enquanto que os impuros fazem mal para a saúde". Portanto, a ideia mais simples é a de que a água mineral é uma substância pura. No rótulo, também está indicada a "composição da água mineral". A palavra composição não é incompreensível, mesmo que o conceito de composição química não tenha sido desenvolvido, pois a palavra em questão está acompanhada de uma lista de nomes de "coisas": bicarbonato de sódio, bicarbonato de magnésio etc.

Um sentido que se pode dar ao conceito de substância, neste momento, é o de que são as "coisas" que estão misturadas à água (outra substância, $\mathrm{H}_{2} \mathrm{O}$ ). Essas "coisas" têm nomes e fórmulas. Quando se comparam rótulos de águas minerais produzidas por empresas diferentes, é fácil concluir que essas "coisas" não fazem parte ou constituem necessariamente a "substância" água, $\mathrm{H}_{2} \mathrm{O}$. A hipótese que se pode construir a partir daí é a de que essas "coisas" são substâncias diferentes que se encontram misturadas à substância água. Assim, o trabalho de construir sentidos para um conceito, como é o caso do conceito de substância, pressupõe um ato de interpretação mediante o estabelecimento de relações entre as palavras e símbolos dispostos nos rótulos e outros textos associados a um núcleo temático que, no caso de nosso exemplo, envolve o conceito de água potável.

A produção de sentidos pressupõe, portanto, intertextualidade e um intenso diálogo constituído pela produção de enunciados e pela escuta entre alunos e professores. Para a realização dessa atividade, são feitas várias perguntas e associações com situações da vida. Por exemplo: será que as substâncias encontradas na água de fontes diferentes são as mesmas?; Qualquer água mineral é constituída das mesmas substâncias?; As substâncias se apresentam na mesma quantidade em diferentes marcas de água?; Como essas substâncias são misturadas à substância água?; Como se explica a indicação, nos rótulos, de composições diferentes em termos de constituintes e da quantidade em que aparecem? Todas essas perguntas compõem um processo de investigação no interior do qual são construídas, paulatinamente, as primeiras aproximações com o conceito de substância.

A palavra, nos diz Vygotsky (2001), não expressa o pensamento, ela o mediatiza: nós pensamos com as palavras. A princípio, o esforço didático foi o de incentivar o estudante a associar a palavra a uma coisa ou objeto: os nomes, as fórmulas concretamente expressos no rótulo. $\mathrm{Na}$ medida em que se enriquecem as interações interlocutivas em sala de aula ou, mesmo, do estudante com a sequência didática proposta pelo livro, a palavra substância passa a não apenas designar o objeto ou as coisas em si, mas a criar generalizações entre conceitos. Nesse processo, pretende-se substituir a relação entre palavra e objeto por relações entre palavras: relações entre substâncias e misturas, entre pureza e potabilidade e, posteriormente, entre substâncias e compostos, moléculas, íons etc. Entendemos essa mudança nos referentes do signo por processo de formação do conceito de substância. Processo que se inicia na atividade descrita e se prolonga em vários capítulos e atividades ao longo da coleção.

Nesse esforço de compartilhar significados com o professor e com os colegas, e reunir diferentes textos produzidos por esses interlocutores ou encontrados nos rótulos de água mineral, o estudante vai se familiarizando com a palavra substância. A intenção é a de que a "palavra do professor" vá, aos poucos, se tornando "palavra própria". A expectativa é a 
de que o estudante pode ter um nível inicial de compreensão do conceito de substância, ao associá-la a nomes e fórmulas apresentados nos rótulos, e compreender que os materiais ocorrem naturalmente misturados. Outros materiais, como o leite, o sangue, o suco, por exemplo, não têm fórmulas. São misturas de substâncias. Retomando Bakhtin (1997b, p. 343): "Ver uma coisa, tomar consciência dela pela primeira vez, significa estabelecer uma relação dialógica com a coisa: ela não existe mais só em si e para si, mas para algum outro (já há uma relação entre duas consciências)."

Ao longo da atividade, os professores acompanham, com atenção, os sentidos que os alunos atribuem às palavras: material, substância, mistura, composto, elementos, entre outras. Os estudantes empregam esses termos com desenvoltura, embora os sentidos atribuídos por eles a essas palavras não correspondam, muitas vezes, ao significado que tais termos têm na ciência. As duas consciências, de que fala Bakhtin (1997b) na citação acima, referem-se aos horizontes conceituais do professor e do aluno. A falta de correspondência entre esses horizontes não impede que os conceitos possam ser utilizados pelos alunos e, desse modo, progressivamente compreendidos e apropriados por eles. $\mathrm{O}$ entendimento da complexidade do processo de formação de conceitos exige de nós, professores, paciência, compromisso e atento acompanhamento. Essa perspectiva dissolve as ilusões de uma aprendizagem fácil e imediata.

A compreensão dos conceitos científicos envolve o encontro destes conceitos com o horizonte conceitual dos estudantes. Esse encontro, algumas vezes, é suave e harmonioso, em outras, permeado por tensões e conflitos. Apropriar-se do conceito científico, nesse sentido, implica relacionar esse conceito com outros, científicos ou não. $\mathrm{Na}$ aprendizagem de conceitos científicos faz-se necessário o reconhecimento de suas particularidades e, em circunstâncias apropriadas, utilizá-los corretamente. Para Bakhtin (1981), a compreensão demanda uma atitude crítica e ativa frente à palavra alheia, um povoamento dessa palavra alheia com suas próprias contrapalavras:

$\mathrm{Na}$ linguagem da vida real, todo ato concreto de compreensão é ativo: o sujeito assimila o mundo a ser compreendido em seu próprio sistema conceitual constituído por objetos específicos e por expressões emocionais, e é indissoluvelmente imerso na resposta, com uma concordância ou discordância motivada. De algum modo, a resposta predomina como princípio ativo: ela cria a base para a compreensão, para uma compreensão ativa e engajada. Compreensão e resposta são dialeticamente imbricadas e mutuamente condicionadas cada uma a outra, uma é impossível sem a outra. (BAKHTIN, 1981, p. 282)

Cientes dessa complexidade, acreditamos que o currículo de ciências deve eleger conceitos estruturadores do pensamento nos diversos campos do conhecimento científico para promover a formação e o desenvolvimento dos mesmos, nos estudantes. O projeto de educação em ciências que defendemos se constitui por meio de idas e vindas em torno dessas ideiaschave, consolidando e ampliando sentidos, à medida que vão sendo revisitados em contextos diversos (AÇÃO E PESQUISA EM EDUCAÇÃO EM CIÊNCIAS, 2003; LIMA; BARBOZA, 2005). Tal concepção de currículo se apoia na ideia de multiplicidade de sentidos de Bakhtin (1997b, p. 414): 
A formação de conceitos científicos: ...

Mesmo os sentidos passados, aqueles que nasceram do diálogo com os séculos passados, nunca estão estabilizados (encerrados, acabados de uma vez por todos). Sempre se modificarão (renovando-se) no desenrolar do diálogo subseqüente, futuro. Em cada um dos pontos do diálogo que se desenrola, existe uma multiplicidade inumerável, ilimitada de sentidos esquecidos, porém, num determinado ponto, no desenrolar do diálogo, ao sabor de sua evolução, eles serão rememorados e renascerão numa forma renovada (num contexto novo).

Em lugar de partir de uma definição, de poucos exemplos e muitos exercícios, a estratégia adotada na escrita da coleção consistiu em apresentar diversos contextos e situações problematizadoras, que permitem, ao estudante, ver essas ideias em funcionamento. Na medida em que se usa uma mesma ideia em situações variadas, o estudante tem a oportunidade de estabelecer maior número de relações entre os sentidos em jogo, o que favorece as condições de apropriação e de consolidação dos conceitos. Como Tolstoi (1961) observou, a nova palavra, uma vez utilizada pelo estudante, em contextos apropriados, ela lhe pertence ou, nos dizeres de Bakhtin (1997b), torna-se palavra própria.

\section{Introduzindo o novo: \\ o papel das problematizações, experimentos e narrativas}

Ensinar ciências implica introduzir os estudantes numa cultura que, inicialmente, não lhes pertence, e dar condições para que eles se apropriem dela e a relacionem com outras dimensões de sua cultura e com a realidade concreta da vida, em suas múltiplas dimensões. Mas, se optamos por não introduzir os conceitos estruturadores das ciências por meio de definições, como então proceder? Que artifícios e estratégias usar para se introduzirem as ideias das ciências e disponibilizá-las para que sejam trabalhadas pelos estudantes? Para Driver et al. (1999, p. 36), "uma maneira de introduzir os estudantes em uma comunidade de conhecimento é através do discurso no contexto de tarefas relevantes."

Em outro texto (LIMA; AGUIAR; BRAGA, 1999, p. 27-28), afirmávamos a importância de se estabelecerem contextos de vivência em que os conceitos científicos possam ser utilizados de maneira adequada como instrumento para compreensão de situações-problema. O modo de perguntar guarda propósitos diferentes, do mesmo modo que gera atitudes de resposta diferentes nos sujeitos aos quais se dirige o texto. $\mathrm{Na}$ coleção de livros didáticos buscamos, muitas vezes, causar um estranhamento em relação aos fatos cotidianos, criando ambiente propício para se introduzirem explicações científicas. Ogborn et al. (1996) chamam essa estratégia de "criar diferenças", e apontam para a importância desse momento como uma preparação da explicação que está por vir.

$\mathrm{Na}$ Figura 2, indicamos uma estratégia de abertura de um capítulo sobre o ciclo e distribuição de água no planeta. 
Lima, M. E. C. C.; Aguiar Júnior, O.; De Caro, C. M.

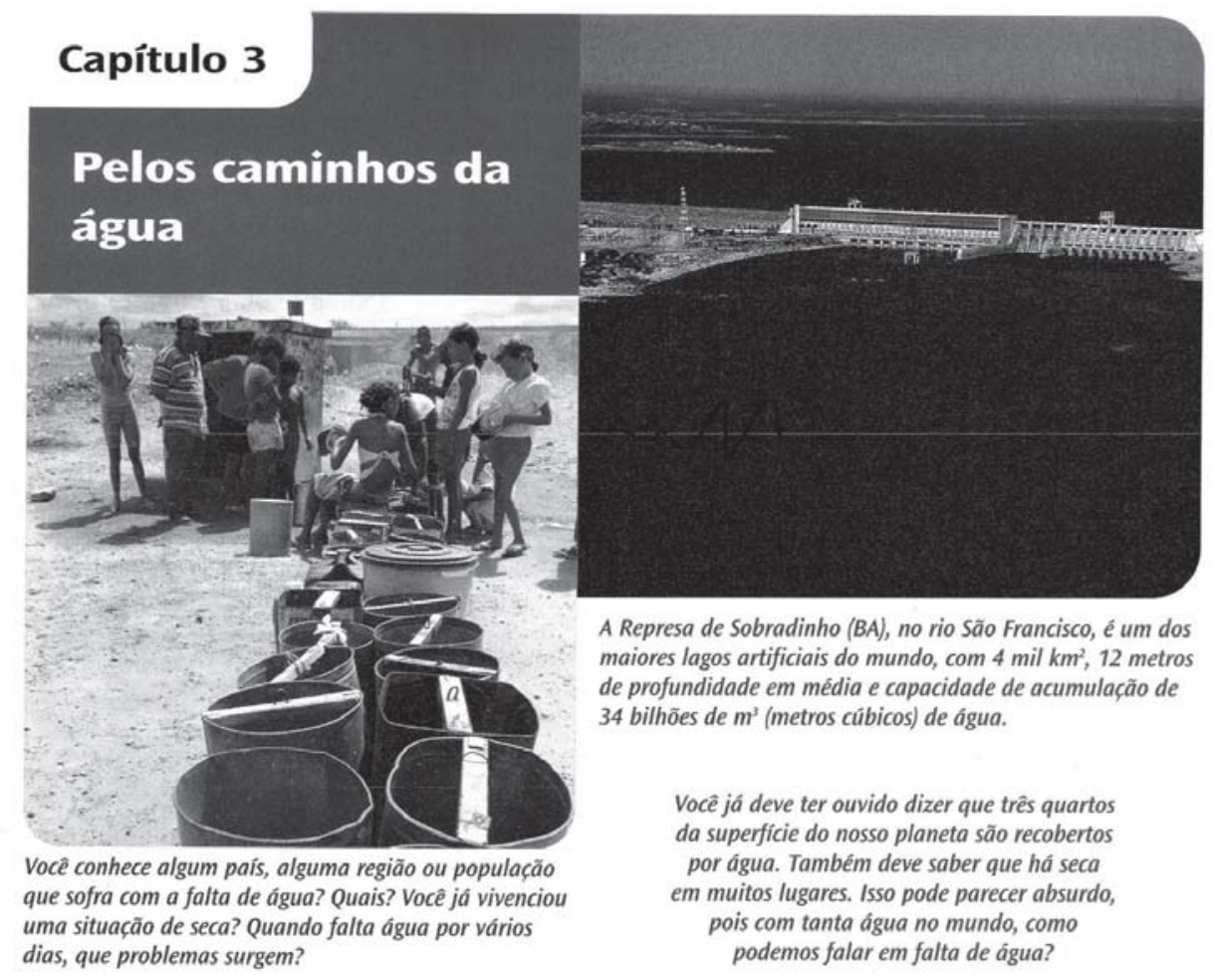

Figura 2. Questões de abertura: com tanta água no mundo, como podemos falar em falta de água?

Fonte: AÇÃO E PESQUISA EM EDUCAÇÃO EM CIÊNCIAS. Construindo consciências - ciências: $5^{a}$ série. São Paulo: Scipione, 2007. p. 51

A estratégia de estranhamento (ou de criação de diferenças) é elemento crucial no processo de ensino e aprendizagem. Esse contexto e modo de perguntar evocam nos estudantes o desejo de uma resposta. Para Bakhtin (1997b), compreensão e resposta à palavra do outro são faces de uma mesma moeda: "Chamo sentido ao que é resposta a uma pergunta. O que não responde a nenhuma pergunta carece de sentido" (BAKHTIN, 1997b, p. 386).

$\mathrm{Na}$ coleção, diferentes estratégias foram usadas para introduzir conceitos científicos no plano coletivo da aula de ciências. No caso dos conceitos de substância e misturas, citados anteriormente, essas palavras são disponibilizadas desde o princípio e os estudantes, de certo modo, são levados a utilizá-las nos sentidos em circulação. Outras vezes, seguimos a máxima de Arons (1984, p. 21): "primeiro a idéia, depois o nome". Essa foi a estratégia que usamos para introduzir o conceito de densidade no capítulo Receitas na medida certa, parte da unidade Ciência na cozinha. Nesse contexto, receitas de culinária são apresentadas com variadas unidades de medida, algumas relativas a medidas de massa, outras a medidas de volume, o que permitiu introduzir questões como: se utilizássemos uma balança para pesar esses ingredientes, uma 
xicara de fubá e uma xícara de farinha teriam a mesma massa? Uma vez estabelecida a diferenciação entre medidas de massa e de volume, passamos, então, a coordená-las, nomeando densidade a relação entre massa e volume, o que significa comparar massas de volumes iguais de diferentes materiais. Uma vez introduzido o conceito, seus sentidos vão sendo expandidos na medida em que ele vai sendo utilizado em diferentes situações. A densidade, compreendida então como propriedade específica de materiais, é então ferramenta em outra atividade, para identificar materiais em um achado arqueológico. Mais adiante, o conceito é retomado no contexto da flutuação de corpos.

A vantagem desse procedimento didático está em inserir elementos que permitam ao estudante apreciar a novidade que o conceito "densidade" introduz. Nesse caso, evitamos antecipar a palavra destituída de sentido. Em lugar disso, buscamos criar a necessidade do conceito para, então, nomeá-lo.

Situações experimentais foram também utilizadas como recurso para se introduzirem conceitos. A prática do ensino de ciências usualmente relega aos experimentos a condição de ilustrar uma explicação já dada. Nesse caso, o experimento perde sua dimensão dialógica e seu valor pedagógico. Ao utilizarmos o experimento na introdução de conceitos e modelos científicos, a intenção que temos é a de ir forjando argumentos a partir de evidências que vão sendo apresentadas, de modo a se construir uma explicação científica. As Figuras 3 e 4 exemplificam o uso desse recurso.
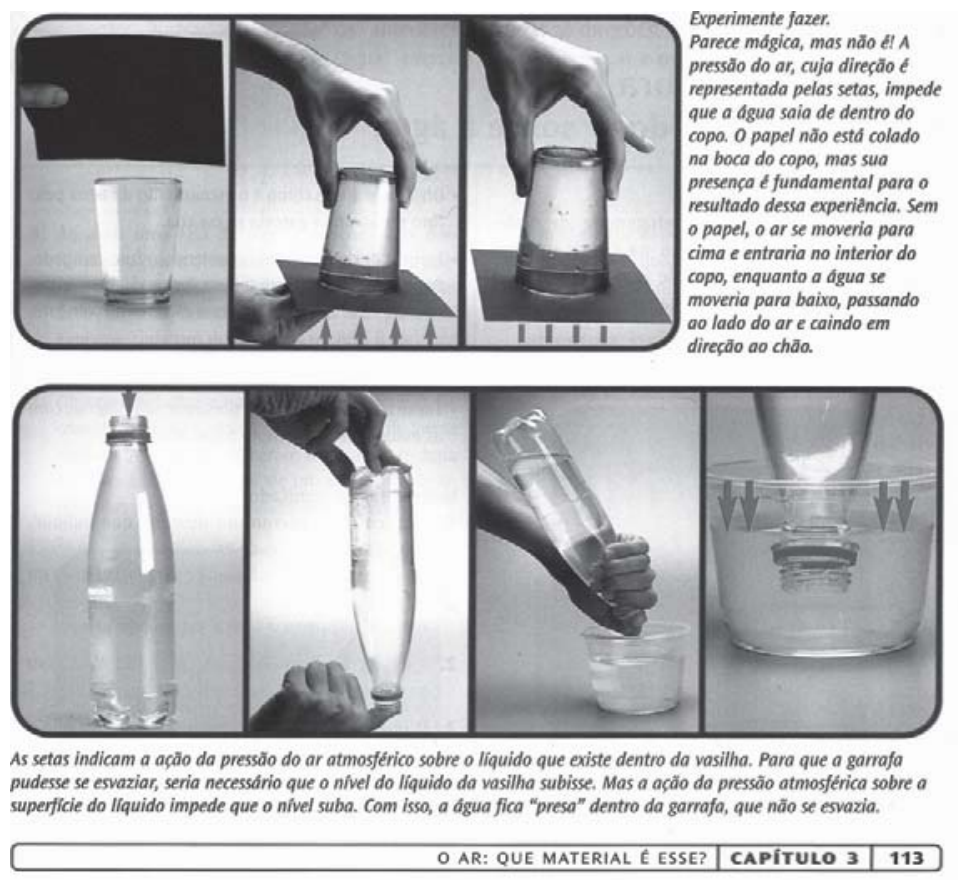

Figura 3. Introduzindo o conceito de pressão atmosférica por meio de experimentos.

Fonte: AÇÃO E PESQUISA EM EDUCAÇÃO EM CIÊNCIAS. Construindo consciências - ciências: $5^{a}$ série. São Paulo: Scipione, 2007. p. 113. 


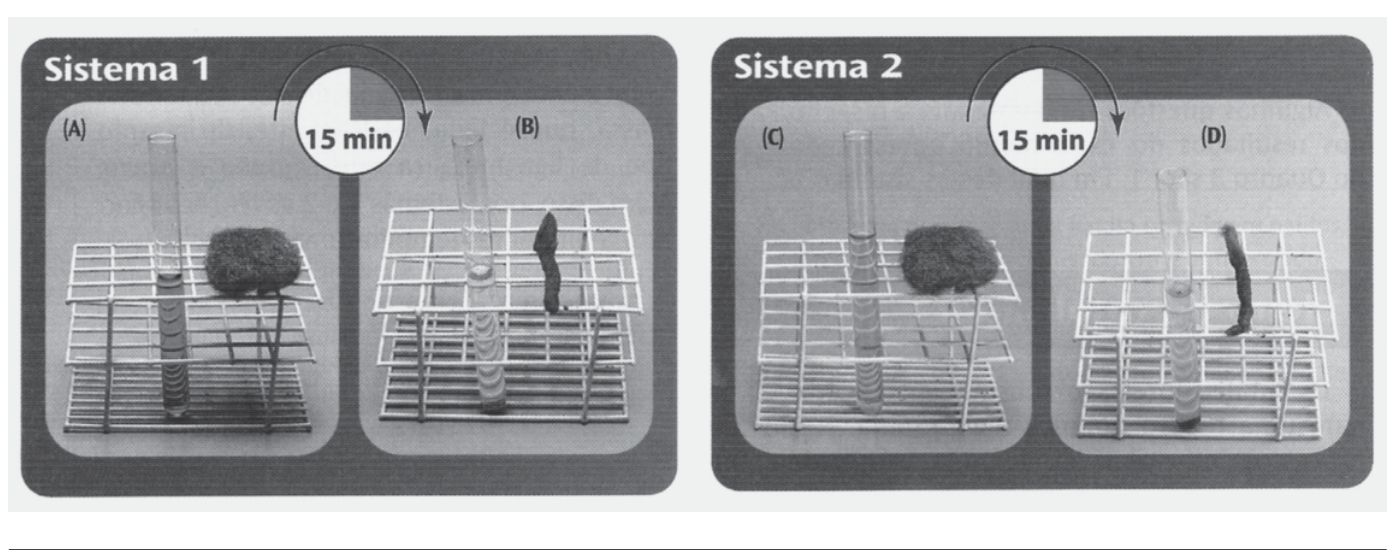

Figura 4. Examinando fatores que alteram a rapidez de reações químicas por meio de experimentos.

Fonte: AÇÃO E PESQUISA EM EDUCAÇÃO EM CIÊNCIAS. Construindo consciências - ciências: $7^{\text {a }}$ série. São Paulo: Scipione, 2007. p. 29

As atividades apresentadas nas Figuras 3 e 4, assim como outras de mesma natureza, receberam críticas de alguns revisores da obra. $\mathrm{Na}$ visão desses colegas, os experimentos eram inadequados, pois os resultados estão apresentados de antemão e discutidos no texto. Os revisores sugeriam o deslocamento dos experimentos para que fossem realizados pelos alunos, depois de um texto formal sobre os assuntos tratados, e sem as figuras que anunciavam os resultados. Discordamos dessa orientação, baseando-nos em nossa experiência docente. Esses experimentos funcionam como recurso textual para se construírem explicações baseadas em evidências. Seu papel é o de auxiliar os estudantes na identificação de evidências e na articulação destas com os conceitos e modelos que vão sendo discutidos e consolidados pelos estudantes.

A narratividade é outro recurso largamente utilizado por nós na apresentação de conceitos e modelos científicos. Esse modo peculiar de ensinar ciências reflete uma concepção que tem o compromisso de enredar o estudante numa história científica, de trazê-lo para o centro da cena. O uso desse gênero de discurso denota uma preocupação dos autores em manter uma comunicação próxima ao estudante e a atenção dos mesmos no desenrolar de uma história. Para Ogborn et al. (1996), as explicações em ciências são como histórias cujos protagonistas são os conceitos abstratos da ciência.

Acreditamos que a narrativa é um modo rico de se intercambiarem experiências. É o gênero por excelência que usamos para conhecer. $\mathrm{O}$ homem aprende narrando, muito embora os textos científicos se orientem por um outro gênero discursivo no qual os sujeitos não têm lugar (LIMA, 2005). Se há algo universal, é a necessidade de narrar. Para Umberto Eco (1995), trata-se de uma necessidade biológica.

A narrativa em si mesma é formadora, pois nela o fluxo da vida, o movimento mesmo da experiência, se sobrepõe às explicações lógicas conectadas por uma relação linear de causaefeito. A narratividade talvez seja a maneira por excelência de constituição do próprio mundo mental (LIMA, 2005). 
A formação de conceitos científicos: ...

Para citar um exemplo, no desenvolvimento do conceito de adaptação e da diversidade de vida, utilizamos largamente o gênero narrativo como estratégia de ensino. O modo de ser e de viver de diversos grupos de animais são apresentados por meio de histórias de vida de alguns representantes da fauna que são conhecidos dos alunos. Para apresentar as características do grupo dos peixes, contamos como vivem as piabas, isto é, como são (morfologia), como se reproduzem, como respiram, como se locomovem e como interagem com o meio em que vivem.

Vida de Piaba - As piabas têm facilidade de viver em corredeiras. Nas primeiras chuvas do ano, esses peixes fazem a piracema. Os gametas do macho e da fêmea - espermatozóides e óvulos - são lançados na água ao mesmo tempo. O encontro dos gametas [...]. (AÇÃO E PESQUISA EM EDUCAÇÃO EM CIÊNCIAS, 2007, p. 162)

Essa narrativa é um gênero textual semelhante àqueles que usamos na vida cotidiana, porém não é qualquer história que é narrada. Foram feitas escolhas, orientadas pelo projeto de dizer do professor de ciências, ou seja, os conteúdos biológicos mais relevantes a serem tratados. A narrativa se contrapõe à descrição usualmente utilizada nos livros didáticos de ciências e de biologia para tratar da morfologia e modos de vida de animais e plantas. O desenrolar da história científica se faz por meio de conceitos - gametas, reprodução, obtenção de energia, entre outros - que são apreciados em um contexto particular (vida de piabas) para, em seguida, serem generalizados para o grupo de peixes e, posteriormente, todos os outros vertebrados.

A narrativa é também explorada nas atividades sugeridas para os estudantes, como se vê nos exemplos a seguir:

O que você aprendeu sobre O Ciclo de Vida de alguns Animais e Vegetais:

Questão 5 - Escreva uma história sobre a vida de uma planta que você conheça a partir de sua germinação. Sua história deverá ter informações sobre o tempo que ela demorou para crescer, características de suas flores e frutos e o modo como as sementes são dispersas. (AÇÃO E PESQUISA EM EDUCAÇÃO EM CIÊNCIAS, 2007, v. 1, p. 50) Ao final de uma atividade sobre Conservação de Alimentos:

Faça um texto sobre o que você já aprendeu lembrando-se de algumas situações que viu em casa, leu no livro ou escutou alguém contar. Não se esqueça que para conservar alimentos é preciso [...]. (AÇÃO E PESQUISA EM EDUCAÇÃO EM CIÊNCIAS, 2007, v. 2, p. 227)

Essas narrativas mesclam aspectos da linguagem científica e cotidiana, permitindo uma aproximação dos estudantes com os modos de falar das ciências. Permitem, além disso, uma reflexão e exame da realidade em que vivem, ou seja, uma interpolação entre os conceitos e modelos abstratos da ciência com a vida cotidiana. 


\section{Por que não usamos glossários?}

Conferimos sentidos às palavras relacionando-as com outras palavras, significados e coisas. Baseando-nos em Bakhtin (1997b) e em nossa experiência pedagógica, afirmamos que a tentativa de preencher vazios conceituais com palavras e definições alheias nos parece uma ilusão. Isso porque, ao tentarmos preencher um vazio, reportamo-noss a outros conceitos e outras ideias, que vão se tornando mais e mais complexos. Consequentemente, vão se criando novos vazios, outros não-ditos ou ditos não compreendidos pelos sujeitos, prática que tem sido corrente em situações de ensino. Vejamos o caso do conceito de matéria a título de exemplo.

Matéria é tudo que tem massa e ocupa lugar no espaço. Massa é quantidade de matéria. Quantidade é uma medida de coisas. Coisas materiais são aquelas que podemos pegar e carregar. Não podemos "pegar energia", no sentido tátil do verbo pegar. Então, a princípio, energia não é matéria. Do ponto de vista da física clássica, energia é uma propriedade termodinâmica de estado do sistema, que pode alterar de valor, durante uma mudança de estado, através da transferência de matéria e/ou trabalho e/ou calor e/ou radiação eletromagnética entre o sistema e as suas vizinhanças.

Exemplos como esse nos levam a concluir que qualquer tentativa de produzir um texto completo, inequívoco e completamente independente de outros textos será em vão. Para adquirir sentido e significado, esse texto pretensamente completo e autocontido nos levaria a uma "história sem fim", na qual criaríamos continuamente novos vazios, outros não-ditos ou outras palavras e ideias não compreendidas pelo ouvinte ou pelo leitor.

Os sentidos que temos das palavras são múltiplos, como são muitos os sujeitos. As palavras não têm um sentido em si mesmas, mas somente quando funcionam articuladas a um conjunto de ideias que queremos expressar. O sentido de uma palavra ou expressão depende, pois, do sentido de palavras e expressões anteriores, ao mesmo tempo em que antecipa o sentido das palavras e expressões que ainda surgirão no fluxo das interações interlocutivas.

\section{À guisa de conclusão}

A fundamentação teórica e os exemplos dados ao longo deste trabalho nos permitem extrair algumas lições para a formação de professores e o desenvolvimento de currículos em ciências. As estratégias que utilizamos para o desenvolvimento de conceitos são variadas, mas não escolhidas ao acaso. Elas fazem parte de um projeto educativo que se sustenta em uma determinada visão de ensino, de aprendizagem. Na perspectiva que adotamos, os sentidos não são dados a priori, mas construídos pelos sujeitos a partir do encontro com outros sujeitos e outros textos, nos fluxos das interações verbais no espaço social da sala de aula.

Defendemos a ideia de que a formação de conceitos é um processo lento, difícil e essencialmente inconcluso. Isso aponta para a necessidade de uma abordagem curricular recursiva com idas e vindas, aprofundamentos, variação de contextos e complexificação de situações a serem abordadas e relacionadas. Aponta, além disso, para a necessidade de se fazer escolhas sobre o que ensinar e sobre as ênfases a serem dadas. Nesse sentido, é importante estabelecer metas para a aprendizagem, ao longo dos níveis de ensino, de "modelos poderosos" (MILLAR, 1996) que estruturam o pensamento científico nos diferentes campos disciplinares. 
A formação de conceitos científicos: ...

Em nosso projeto de ensino, agora materializado em coleção de textos didáticos de ciências, defendemos a formação de conceitos científicos pelo uso funcional de sua linguagem em contextos de relevância para os estudantes. Essa perspectiva se contrapõe ao uso precoce e fechado de definições, entendidas, por nós, como coroamento de um processo, e não como ponto de partida.

A compreensão é, assim, um trabalho verbal de construção de sentidos, da apropriação do conceito. Emerge nas interações interlocutivas, no confronto entre falantes, no ato mesmo da linguagem. O termo apropriação está sendo usado aqui deliberadamente para marcar a posse do sujeito sobre algo que antes não lhe pertencia porque, externo a ele, só guardava o sentido atribuído pelo enunciador, quer seja este o livro didático ou o professor.

Esse tipo de abordagem elimina um impasse nos currículos de ciências. Muitos conceitos centrais nas ciências apresentam definições complexas e difíceis de serem introduzidas e assimiladas pelos estudantes no Ensino Fundamental. Além do conceito de substância, aqui analisado, podemos citar outros como: energia, calor, fotossíntese, espécie e adaptação. Nesses casos, definições precoces muitas vezes atrapalham mais que ajudam. O impasse está em considerar que, não podendo defini-los com precisão, não devem ser objeto do Ensino Fundamental, o que cria problemas, pois são ideias-chave na compreensão das ciências. Sendo conceitos complexos, essa é mais uma razão para que sejam apresentados recursivamente nos vários níveis de ensino, em diferentes contextos e níveis de complexidade.

Isso implica a necessidade de se introduzir essa linguagem na relação com outras linguagens sociais, indicando suas diferenças e particularidades. Nessa concepção, é fundamental que, nas aulas de ciências, as crianças e jovens tenham amplas e variadas oportunidades de utilizarem as linguagens da ciência.

Parafraseando Oliveira (1999), podemos depurar três 'lições' dos exemplos relatados neste artigo sobre o processo de formação de conceitos. A primeira delas é a de que as definições, em geral, constituem uma etapa tardia no desenvolvimento de conceitos e, em alguns casos, nem chegam a se configurarem como tal. A segunda é a de que o desenvolvimento de conceitos envolve o reconhecimento, pelos estudantes, dos contextos que demandam seu uso para o entendimento do mundo. A terceira lição é a de que o processo de formação de conceitos científicos consiste no desenvolvimento de formas específicas de falar sobre e com o mundo, modos de dizer que carregam significados e relações com outros conceitos.

Ao considerarmos o conceito como um meio importante de apropriação do conhecimento científico, valorizamos a formação de conceitos não só como ferramenta para compreender o mundo, mas como processo que modifica de maneira substantiva o conteúdo do pensamento humano e que potencializa o desenvolvimento das funções mentais superiores. 
Lima, M. E. C. C.; Aguiar Júnior, O.; De Caro, C. M.

\section{Referências}

AÇÃO E PESQUISA EM EDUCAÇÃO EM CIÊNCIAS. Por um novo currículo de ciências para as necessidades de nosso tempo. Presença Pedagógica, Belo Horizonte, v. 9, n. 51, p. 43-55, 2003.

Construindo consciências: ciências. 2. ed. São Paulo: Scipione, 2007. 4 v.

AGUIAR JÚNIOR, O. Professores, reformas curriculares e livros didáticos de ciências: parâmetros para produção e avaliação do livro didático. In: ENCONTRO DE PESQUISA EM ENSINO DE FÍSICA, EPEF, 9., 2004, São Paulo. Anais... São Paulo: Sociedade Brasileira de Física, 2004. 1 cd-rom.

ARONS, A. Students' patterns of thinking and reasoning. Part II. The Physics Teacher, v. 22, n. 1, p. 21-26, 1984.

BAKHTIN, M. M. Marxismo e filosofia da linguagem. São Paulo: Hucitec, 1997a.

Estética da criação verbal. São Paulo: Martins Fontes, 1997b.

Discourse in the novel. In: (Org.). The dialogic imagination: four essays. Austin: University of Texas Press, 1981. p. 259-422.

BRAIT, B. (Org.). Bakhtin: conceitos chave. São Paulo: Contexto, 2005.

DRIVER, R. et al. Construindo conhecimento científico em sala de aula. Trad. Eduardo Mortimer. Química Nova na Escola, São Paulo, n. 9, p. 31-40, 1999.

ECO, U. A ilha do dia anterior. 5. ed. Rio de Janeiro: Record, 1995.

FONTANA, R. C. Mediação pedagógica na sala de aula. Campinas: Autores Associados, 1996.

FREITAS, M. T. A. Vygotsky e Bakhtin: psicologia e educação - um intertexto. São Paulo: Ática, 1995.

LIMA, M. E. C. C. Sentidos do trabalho: a educação continuada de professores. Belo Horizonte: Autêntica, 2005.

LIMA, M. E. C. C.; AGUIAR JR., O.; BRAGA, S. M. Aprender ciências: um mundo de materiais - livro do professor. Belo Horizonte: Editora UFMG, 1999.

LIMA, M. E. C. C.; BARBOZA, L. C. Idéias estruturadoras do pensamento químico. Química Nova na Escola, São Paulo, n. 21, p. 39-43, 2005.

LIMA, M. E. C. C.; SILVA, N. S. A química no ensino fundamental: uma proposta em ação. In: ZANON, L. B.; MALDANER, O. A. (Orgs.). Fundamentos e propostas de ensino de química para a educação básica. Ijuí: Ed. Unijuí, 2007. p. 89-107. 
A formação de conceitos científicos: ...

MACHADO, A. H. Aula de Química. Ijuí: Ed. Unijuí, 1999.

MILLAR, R. Science curriculum for all. School Science Review, London, v. 77, n. 280, p. 7-18, 1996.

MORTIMER, E. F. Linguagem e formação de conceitos no ensino de ciências. Belo Horizonte: Editora UFMG, 2000.

O ensino de química e ciências e a problemática conceitual. In: ENCONTRO CENTRO-OESTE DE DEBATES SOBRE ENSINO DE QUÍMICA E CIÊNCIAS, ECODEQC, 7., 1995, São Paulo. Palestra ... São Paulo: Sociedade Brasileira de Química, 1995. (mimeogr.).

OGBORN, J. et al. Explaining science in the classroom. Buckingham: Open University Press, 1996.

OLIVEIRA, M. K. Três questões sobre desenvolvimento conceitual. In: OLIVEIRA, M. B.; OLIVEIRA, M. K. (Orgs.). Investigações cognitivas. Porto Alegre: Artes Médicas, 1999. p. 55-64.

TOLSTOI, L. Obras pedagógicas. Moscovo: Edições Progresso, 1961.

VYGOTSKY, L. S. Pensamento e linguagem. São Paulo: Martins Fontes, 1991. 2001.

A construção do pensamento e da linguagem. São Paulo: Martins Fontes,

YAGUELLO, M. Introdução. In: BAKHTIN, M. (Org.). Marxismo e filosofia da linguagem. 8. ed. São Paulo: Hucitec, 1997. p. 11-19.

WERTSCH, J. Mind as action. New York: Oxford University Press, 1998.

Artigo recebido em 25/07/2010. Aceito em 21/02/2011. 